\title{
SOME MECHANICAL CHARACTERISTICS OF AMALGAMATORS
}

N. O. TAYLOR, PH.D.,* W. T. SWEENEY, A.B., † AND D. B. MAHLER, M.S. University of Michigan, School of Dentistry, Ann Arbor, Mich.

I T HAS been well established that the characteristics of dental amalgams are subject to wide variation as the result of changes in formulae, manufacturing methods, and trituration and packing procedures.

Trituration and packing procedures are under the control of the operator. In any given alloy we expect to find that undertrituration will produce low crushing strength, high flow and higher than normal expansion in finished amalgams. The proper amount of work applied during amalgamation will provide acceptable expansion (3-13 microns per $\mathrm{cm}$.) and less than 4 per cent flow in all alloys "Certified" to the Research Council of the American Dental Association. Overworking will increase flow values and will decrease expansion if it does not actually eause shrinkage in the final fillings.

The susceptibility of alloys to such ehanges may vary widely from one product to another, some being markedly stable eompared with others, but variations of 15 per cent in the mereury-alloy ratio have been shown by Phillips and Boyd $^{1}$ to have marked effects on the properties of amalgams and presumably variations of 10 per cent may be significant.

In recent months there appears to have been an increasing interest in mechanical amalgamators. Individuals are undoubtedly led to consider these devices because of their desire to do this type of work as easily and conveniently as possible, and in many cases it seems that claims for speed and convenience have been so alluring the purchasers have neglected to question the effects of the instruments on the properties of finished restorations.

Since the effects of variations in working have been so well established, and further, considering the increasing use of mechanical amalgamators, it appears that every factor governing the use of the instruments should be considered.

Mechanical devices to facilitate the amalgamation of alloy particles with mercury for use in dental restorations have been offered the dental profession for many years. The saving of time and the increased convenience have been emphasized. Mechanieal amalgamators seldom have been accompanied by adequate directions from either the manufacturers of the instrument or of the alloy, and the user has been left to his own devices in working out a satisfactory method for its use. Under these circumstances we find that some consideration has been given to the effects of mechanical trituration on different types of alloys, but little if any to the mechanical characteristies of the instrument which might vary the amounts of work done and so affect the characteristies of the finished amalgams.

This study was supported by the Office of Naval Research.

Received for publication, September 27, 1949.

* Present address, The S. S. White Dental Mfg. Co., Philadelphia, Pa.

†Present address, National Bureau of Standards, Washington, D. C. 
It is well established that a variety of factors may definitely influence the final properties of amalgams. These are factors under the control of the manufacturer:

1. The formula selected.

2. The preliminary annealing (if any) of the cast bars of alloy.

3 . The gradation of particle size and shape.

4. The final annealing and cleaning of the particles.

The manufacturer is expected to supply a product to meet the requirements of the American Dental Association Specification No. 1 for Dental Amalgam Alloy, and therefore must select a formula and control his methods carefully to give an alloy of acceptable quality. He must also supply adequate directions for the use of his product. These directions must cover those factors under the control of the operator which may affect the quality of the finished restoration, namely :

5. The proportion of alloy to mereury.

6. Mixing procedure involving:

a. Mixing time.

b. Rate of pestle rotation.

c. Pressure on pestle, all assuming that the size of the mortar is correct for the size of the mix, the fit of the pestle to the mortar is close, and the surfaces of both mortar and pestle are clean and etched to permit efficient mixing.

d. The time elapsing between mixing and packing.

e. The method of expressing excess mercury before packing.

f. Packing procedures which include such factors as the size and shape of instrument surfaces, and the forces applied to them.

In packing amalgams the amount of mercury expressed affects both flow and expansion. Low packing pressures or prolonged working times will give higher than normal expansions and flow, and low erushing strength. High pressures will lower expansion and flow.

Sedimentation or separation of alloy particles into portions having different particle sizes will also affect final results, the finer sizes amalgamating more rapidly and having lower expansion and higher flow. ${ }^{2}$ Mechanical amalgamators are recommended to facilitate the mixing of alloys with mereury, and to save time by reducing the mixing time to a matter of a few seconds. Granting that the mixing of amalgams is a critical process, it appears that any speedup of the correct mixing process must be carefully evaluated and controlled if undesirable effects are to be avoided. Also, the amount of time required to mix different alloys eurrently used is quite varied, as shown by the "normal mixing time" on a particular amalgamator (Rose) reported by the authors on five dental alloys as $8,13,15,20$, and 20 seconds, respectively. ${ }^{3}$

This study of the mechanical characteristics of amalgamators was initiated with the object of estimating possible damaging effects of mechanical amalgamation upon the properties of the finished amalgam restorations. 
A group of mechanical devices which were operated through the conventional handpiece was given no more than casual consideration. This type of equipment can be passed over quickly by observing that it is operated without timing controls, and that its speed depends upon the speed of the motor used and the belt slippage. The variables appear so great that little hope can be held out for controlled amalgamation. Little information could be gained by detailed study of them. Their effects on either amalgams or handpieces are uncontrolled and are almost certainly harmful to both.

The group of amalgamators most popular are those driven by small motors which are part of the unit itself. Three types of these were studied to determine possible effects of their mechanical characteristics upon amalgams made in them. The amalgamators studied were:

A. The Wig $L$ Bug.--This has a synchronous motor and a timer which can be set for a given time interval and which stops the machine at the expiration of that interval, once the starting switch is thrown. The alloy and mercury are shaken with a reciprocating motion in either a metal or plastic capsule with or without a small metal pestle.

B. The Rose Amalgamator.-This machine is driven by a small motor and amalgamates the alloy and mercury by shaking them together in a eylindrical plastic container (pillbox) with a rotary action. The machine is started by turning a switch against' an adjustable stop. 'This starts the motor which operates until a switch mounted on the shaft of a reducing gear breaks the circuit.

C. The Flossy Amalgamator.-A small motor drives this machine which uses a reciprocating shaking action to obtain amalgamation. Timing is controlled by a lever which operates a timing device and also starts the motor.

Inasmuch as any factor which changes the amount of work done on an alloy-mercury mixture during amalgamation will affect the finished properties, studies were made of these amalgamators to determine: (1) Accuracy of timing; (2) effects of voltage variation; and (3) effects of size of load.

The equipment used to control and measure variables included: (1) A small variable transformer which made it possible to operate the instruments on all voltages within the $100-120$ volt ranges encountered in service; (2) a high grade volt meter to indicate voltages supplied; (3) stop watches and an electrical laboratory timer; and (4) a General Electric Company Strobotac-a stroboscopic instrument for determining the motor speeds to an accuracy approximating 10 r.p.m.

Line voltages in dental offices vary with location, total line load, and external light conditions, and variations from 100 to 120 volts may be encountered on 110 volt lines.

Speeds of the instruments were determined when operating at various voltages and under various load conditions and the data secured are shown in Table I.

The Wig L Bug, having a synchronous motor, operates at almost constant speed. The power of its motor is limited and this, together with the space limitations of its capsules, makes it inadvisable to make mixes larger than 12 
TABLE I

SPEed Variations of AMalgamators

\begin{tabular}{|c|c|c|c|c|c|}
\hline \multirow[b]{2}{*}{$\begin{array}{l}\text { VOLTAGE } \\
\text { (60 CYCLE } \\
\text { A.C.) }\end{array}$} & \multirow[b]{2}{*}{$\begin{array}{l}\text { LOAD } \\
\text { (GR.) }\end{array}$} & \multirow[b]{2}{*}{$\begin{array}{c}\text { ROSE } \\
\text { AMALGAMATOR } \\
\text { (R.P.M.) }\end{array}$} & \multirow[b]{2}{*}{$\begin{array}{c}\text { FLOSSY } \\
\text { AMALGAMATOR } \\
\text { (R.P.M.) }\end{array}$} & \multicolumn{2}{|c|}{ WIG Is BUG } \\
\hline & & & & $\begin{array}{l}\text { WITH PESTLE } \\
\text { (R.P.M.) }\end{array}$ & $\begin{array}{l}\text { WITHOUT } \\
\text { PESTLE } \\
\text { (R.P.M.) }\end{array}$ \\
\hline 100 & $\begin{array}{c}\text { empty } \\
6 \\
12 \\
18\end{array}$ & $\begin{array}{l}1490 \\
1465 \\
1365 \\
1310\end{array}$ & $\begin{array}{l}1925 \\
1780 \\
1700 \\
1540\end{array}$ & $\begin{array}{l}1380 \\
1300 \\
1290 \\
1330 \\
\end{array}$ & $\begin{array}{l}1470 \\
1440 \\
1420 \\
1370 \\
\end{array}$ \\
\hline 105 & $\begin{array}{c}\text { empty } \\
6 \\
12 \\
18\end{array}$ & $\begin{array}{l}1500 \\
1480 \\
1390 \\
1350\end{array}$ & $\begin{array}{l}1990 \\
1890 \\
1780 \\
1670\end{array}$ & $\begin{array}{l}1420 \\
1370 \\
1345 \\
1365\end{array}$ & $\begin{array}{l}1510 \\
1490 \\
1470 \\
1430\end{array}$ \\
\hline 110 & $\begin{array}{c}\text { empty } \\
6 \\
12 \\
18\end{array}$ & $\begin{array}{l}1510 \\
1500 \\
1410 \\
1380\end{array}$ & $\begin{array}{l}2040 \\
1960 \\
1860 \\
1790\end{array}$ & $\begin{array}{l}14 \overline{60} \\
1430 \\
1400 \\
1400\end{array}$ & $\begin{array}{l}1550 \\
1520 \\
1500 \\
1470\end{array}$ \\
\hline 115 & $\begin{array}{c}\text { empty } \\
6 \\
12 \\
18\end{array}$ & $\begin{array}{l}15 \overline{40} \\
1505 \\
1450 \\
1400\end{array}$ & $\begin{array}{l}2040 \\
2020 \\
1930 \\
1900\end{array}$ & $\begin{array}{l}1490 \\
1470 \\
1440 \\
1440\end{array}$ & $\begin{array}{l}1565 \\
1550 \\
1525 \\
1500\end{array}$ \\
\hline 120 & $\begin{array}{c}\text { empty } \\
6 \\
12 \\
18\end{array}$ & $\begin{array}{l}1565 \\
1520 \\
1460 \\
1420\end{array}$ & $\begin{array}{l}20 \overline{60} \\
2090 \\
1990 \\
1950\end{array}$ & $\begin{array}{l}1510 \\
1490 \\
1465 \\
1470\end{array}$ & $\begin{array}{l}1575 \\
1560 \\
1550 \\
1515\end{array}$ \\
\hline
\end{tabular}

*The manufacturer advertises a speed of 2500 r.p.m. When first received this machine operated at approximately that speed, but after comparatively little use the speed dropped to the Ievels shown.

grains of alloy plus the required amounts of mercury. The Rose instrument after months of regular use operates at the same speed as when received. Its capsules are also too small to handle larger than 12 grain mixes satisfactorily. A new Flossy instrument operated at 2500 r.p.m. on 110 volts when received, but in a comparatively short time and with relatively little use it changed enough that its operating speed dropped to 2000 r.p.m. (20 per cent).

I. Timing.-The timer of the Wig L Bug, being set independently, will give as great a uniformity in time intervals as the operator's uniformity in setting it. Inasmuch as the time intervals used are short, care in setting the timer is an important factor in the use of the machine.

The timing of the Rose Mixer is mechanical and if the starting switch is turned promptly to the stop and released, the machine will operate for a fixed number of revolutions and stop. It should be noted here that though the speed of the motor may be changed by changes in load or voltage, the total number of revolutions will be unchanged, and if the speed variations are not abnormal, the amalgamation produced will be reasonably uniform.

The timer of the Flossy machine has the starting switch incorporated into it. The scale indicating time intervals is small and individuals vary in the time taken to get the desired setting; results were erratic enough to indicate undesirable irregularity of performance. Four operators were used in timing tests on this machine, setting certain time intervals which were checked against actual time of operation. 
II. Effects of Voltage and Loading.--The three machines were studied when operating on controlled voltages within normal operating limits and with different loadings. The loads used were 6, 12, and 18 grains of alloy, and alloy to mercury proportions were all 5:7. Speeds were checked with a General Electric Strobotac.

\section{SUM MARY}

1. Mechanical mixers operated on handpieces, being so variable in performance, are not recommended for use if an operator hopes to produce high grade restorations consistently.

2. The Flossy Amalgamator showed poor timing control and variations in motor speed.

3. The Wig L Bug was only slightly affected by voltage variations, but practical experience with it indicated that it should not be used for mixes larger than 12 grains of alloy.

4. The Rose Mixer has the same load limit as the Wig L Bug. The timing device is quite uniform for loads of 12 grains.

5. It is suggested that the best way to use an amalgamator in the absence of specific directions for the use of the alloy at hand would be to make several mixes by hand and then make several mixes under varying conditions with the machine. Then by comparing the satisfactory mix obtained by hand with the mechanical mixes, the time and conditions can be fairly well established.

\section{REFERENCES}

1. Phillips, R. W., and Boyd, D. A.: Importance of the Mercury-Alloy Ratio to the Amalgam Filling, J.A.D.A. 34: 451, 1947.

2. Jarabak, J. R.: The Effect of Particle Size on Dimensional Change in Dental Amalgam, J.A.D.A. 29: $593,1942$.

3. Taylor, N. O., Sweeney, W. T., Mahler, D. B., and Dinger, E. J.: The Effects of Variable Factors on Crushing Strengths of Dental Amalgams, J. D. Res. 28: 228, 1949. 